\title{
Using Ultrafast X-ray Spectroscopy To Address Questions in Ligand-Field Theory: The Excited State Spin and Structure of [Fe(dcpp)2]2
}

Britz, Alexander; Gawelda, Wojciech; Assefa, Tadesse A.; Jamula, Lindsey L.; Yarranton, Jonathan T.; Galler, Andreas; Khakhulin, Dmitry; Diez, Michael; Harder, Manuel; Doumy, Gilles

Total number of authors:

28

Published in:

Inorganic Chemistry

Link to article, DOI:

10.1021/acs.inorgchem.9b01063

Publication date:

2019

Document Version

Peer reviewed version

Link back to DTU Orbit

Citation $(A P A)$ :

Britz, A., Gawelda, W., Assefa, T. A., Jamula, L. L., Yarranton, J. T., Galler, A., Khakhulin, D., Diez, M., Harder, M., Doumy, G., March, A. M., Bajnóczi, É., Németh, Z., Pápai, M. I., Rozsályi, E., Sárosiné Szemes, D., Cho, H., Mukherjee, S., Liu, C., ... McCusker, J. K. (2019). Using Ultrafast X-ray Spectroscopy To Address Questions in Ligand-Field Theory: The Excited State Spin and Structure of [Fe(dcpp)2]2. Inorganic Chemistry, 58(14), 93419350. https://doi.org/10.1021/acs.inorgchem.9b01063

\section{General rights}

Copyright and moral rights for the publications made accessible in the public portal are retained by the authors and/or other copyright owners and it is a condition of accessing publications that users recognise and abide by the legal requirements associated with these rights.

- Users may download and print one copy of any publication from the public portal for the purpose of private study or research.

- You may not further distribute the material or use it for any profit-making activity or commercial gain

- You may freely distribute the URL identifying the publication in the public portal 


\title{
Using Ultrafast X-ray Spectroscopy to Address Questions in Ligand-field Theory: The Excited State Spin and Structure of $\left[\mathrm{Fe}(\mathrm{dcpp})_{2}\right]^{2+}$
}

\author{
Alexander Britz ${ }^{* 1,2, \#}$, Wojciech Gawelda ${ }^{* 1,3}$, Tadesse A. Assefa ${ }^{1,4+}$, Lindsey L. Jamula ${ }^{5}$, \\ Jonathan T. Yarranton ${ }^{5}$, Andreas Galler ${ }^{1}$, Dmitry Khakhulin ${ }^{1,2}$, Michael Diez, ${ }^{1,2}$, Manuel \\ Harder $^{6}$, Gilles Doumy ${ }^{7}$, Anne Marie March ${ }^{7}$, Éva Bajnóczi $^{8}, Z_{\text {Zoltán Németh }}^{8}$, Mátyás Pápai ${ }^{8,9}$, \\ Emese Rozsályi ${ }^{8}$, Dorottya Sárosiné Szemes ${ }^{8,}$ Hana Cho $^{10}$, Sriparna Mukherjee ${ }^{11}$, Chang Liu, ${ }^{11}$ \\ Tae Kyu Kim ${ }^{12}$, Robert W. Schoenlein ${ }^{13, \#}$, Stephen H. Southworth ${ }^{7}$, Linda Young, ${ }^{76}$, Elena \\ Jakubikova $^{11}$, Nils Huse ${ }^{14,15}$, György Vankó ${ }^{8}$, Christian Bressler ${ }^{* 1,2}$, and James K. McCusker ${ }^{*, 5}$ \\ ${ }^{1}$ European XFEL, Holzkoppel 4, 22869 Schenefeld, Germany \\ ${ }^{2}$ The Hamburg Centre for Ultrafast Imaging, Luruper Chaussee 149, 22761 Hamburg, Germany \\ ${ }^{3}$ Faculty of Physics, Adam Mickiewicz University, Umultowska 85, 61-614 Poznań, Poland \\ ${ }^{4}$ University of Hamburg, Institute of Laser Physics, Luruper Chaussee 149, 22761 Hamburg, Germany \\ ${ }^{5}$ Department of Chemistry, Michigan State University, East Lansing, MI 48824, USA \\ ${ }^{6}$ Deutsches Elektronen-Synchrotron DESY, Notkestrasse 85, 22607 Hamburg, Germany \\ ${ }^{7}$ Chemical Sciences and Engineering Division, Argonne National Laboratory, Argonne, Illinois 60439, USA \\ ${ }^{8}$ Wigner Research Centre for Physics, Hungarian Academy Sciences, H-1525 Budapest, Hungary \\ ${ }^{9}$ Department of Chemistry, Technical University of Denmark, DK-2800, Kongens Lyngby, Denmark \\ ${ }^{10}$ Center for Analytical Chemistry, Division of Chemical and Medical Metrology, Korea Research Institute of Standards and \\ Science, Daejeon 34113, Rep. of Korea \\ ${ }^{11}$ Department of Chemistry, North Carolina State University, Raleigh, NC 27695, USA \\ ${ }^{12}$ Department of Chemistry and Chemistry Institute of Functional Materials, Pusan National University, Busan 46241, Rep. of \\ Korea \\ ${ }^{13}$ Ultrafast X-ray Science Laboratory, Lawrence Berkeley National Laboratory, Berkeley, USA \\ ${ }^{14}$ University of Hamburg, Center for Free-Electron Laser Science, Hamburg, Germany \\ ${ }^{15}$ Max Planck Institute for the Structure and Dynamics of Matter, Hamburg, Germany \\ ${ }^{16}$ Department of Physics and The James Franck Institute, The University of Chicago, Chicago, IL, USA
}


Present addresses: \#Stanford PULSE Institute, SLAC National Accelerator Laboratory, Menlo Park, CA 94025, USA and Linac Coherent Light Source, SLAC National Accelerator Laboratory, Menlo Park, CA 94025, USA, ${ }^{+}$Condensed Matter and Material Science Department, Brookhaven National Laboratory, Upton, NY 11793, USA

Keywords: Ultrafast x-ray absorption and emission spectroscopy, ligand-field excited states, Febased photophysics

\section{ABSTRACT}

We have employed a range of ultrafast $\mathrm{x}$-ray spectroscopies in an effort to characterize the lowest energy excited state of $\left[\mathrm{Fe}(\mathrm{dcpp})_{2}\right]^{2+}$ (where dcpp is 2,6-(dicarboxypyridyl)pyridine). This compound exhibits an unusually short excited-state lifetime for a low-spin Fe(II) polypyridyl complex of $270 \mathrm{ps}$ in room-temperature fluid solution, raising questions as to whether the ligand-field strength of dcpp had pushed this system beyond the ${ }^{5} \mathrm{~T}_{2} /{ }^{3} \mathrm{~T}_{1}$ crossing point and stabilizing the latter as the lowest energy excited state. $\mathrm{K} \alpha$ and $\mathrm{K} \beta \mathrm{x}$-ray emission spectroscopies have been used to unambiguously determine the quintet spin multiplicity of the long-lived excited state, thereby establishing the ${ }^{5} \mathrm{~T}_{2}$ state as the lowest energy excited state of this compound. Geometric changes associated with the photo-induced ligand-field state conversion have also been monitored with extended x-ray absorption fine structure. The data show the typical average Fe-ligand bond length elongation of $\sim 0.18 \AA$ for a ${ }^{5} \mathrm{~T}_{2}$ state and suggest a high anisotropy of the primary coordination sphere around the metal center in the excited ${ }^{5} \mathrm{~T}_{2}$ state, in stark contrast to the nearly perfect octahedral symmetry that characterizes the low-spin ${ }^{1} \mathrm{~A}_{1}$ ground state structure. This study illustrates how the application of time-resolved x-ray techniques can provide insights into the electronic structures of molecules - particularly transition metal complexes - that are difficult if not impossible to obtain by other means. 


\section{INTRODUCTION}

The capture and conversion of light into electrical and/or chemical energy is one of the most promising venues for addressing energy needs on a global scale. As in nature, molecular or materials-based approaches require as a first step the separation of charge: the chemical potential this charge separation creates is what drives subsequent processes such as current generation in solar cells ${ }^{1}$ or the coupling of redox equivalents to catalysts for the formation of energy-dense compounds ${ }^{2}$. In terms of kinetics, the lifetime of this charge separated state must be sufficiently long relative to the processes reliant on the redox activity of the excited state to effect subsequent chemical dynamics. For strategies that employ transition metal-based compounds, complexes of the second- and third-row transition series (e.g., Ru, Ir) are characterized by metal-to-ligand charge transfer (MLCT) excited states possessing excited-state lifetimes that can range from tens of nanoseconds to many microseconds, thereby allowing for their use in a wide range of settings, including bimolecular reaction chemistry ${ }^{3}$. Unfortunately, these elements represent some of the least abundant of the entire periodic table. Although this is not necessarily a problem when incorporated into catalysts - many large-scale industrial reactions use compounds based on rhenium, for example - the diffuse nature of sunlight makes the light capture part of the solar energy conversion problem material-intensive. The elemental availability of the components making up the chromophore is therefore a critical issue when it comes to scalability.

To overcome this problem in the context of transition metal-based chromophores, one would want to replace rare $4 \mathrm{~d} / 5 \mathrm{~d}$ complexes with more earth-abundant first-row (3d) complexes. Successful efforts along these lines have employed $\mathrm{Cu}(\mathrm{I})$. For example, a Cu-based photosensitizer has been employed in a homogeneous water splitting system; ${ }^{4}$ and $\mathrm{Cu}(\mathrm{I})$-based polypyridyl complexes have been used as chromophores in dye-sensitized solar cells (DSSCs). ${ }^{5}$ The $\mathrm{d}^{10}$ 
configuration of $\mathrm{Cu}(\mathrm{I})$ gives it an electronic structure reminiscent of $\mathrm{Ru}(\mathrm{II})$ (i.e., the lowest-energy excited state of polypyridyl complexes of $\mathrm{Cu}(\mathrm{I})$ is a ${ }^{3} \mathrm{MLCT}$ ), so the ability of these complexes to engage in photo-induced electron transfer is not surprising. More challenging has been the use of iron, the first-row congener of ruthenium. An enormous number of low-spin (LS) Fe(II) complexes are known, including the thoroughly studied $\mathrm{Fe}(\mathrm{II})$ polypyridyl complexes $\left[\mathrm{Fe}(\mathrm{bpy})_{3}\right]^{2+6-8}$ and $\left[\mathrm{Fe}(\text { terpy })_{2}\right]^{2+}{ }^{9-12}$. Their absorption spectra are dominated by strong MLCT transitions in the visible regime, however, these $\mathrm{Fe}(\mathrm{II})$-based complexes have been difficult to employ in solar energy conversion schemes ${ }^{5}$ due primarily to the fact the MLCT states convert to lower-lying metal-centered ligand-field (LF) states on the $\sim 100 \mathrm{fs}$ timescale ${ }^{8,13-16}$. Although the underlying reason(s) driving these surprisingly rapid dynamics are still the subject of active research, ${ }^{17}$ recent calculations suggest that the potential energy surfaces of these ligand-field excited states cross those of the MLCT states in proximity of the Franck-Condon regime. ${ }^{18,19}$ This can lead to efficient non-radiative decay through coupling of states at conical intersections.

One approach to eliminating the problem of rapid deactivation of MLCT states in Fe-based chromophores has been to design ligands that impart substantially stronger ligand fields to the metal center. This should result in destabilization of multielectronic terms states that arise due to population of the $e_{g}{ }^{*}$ orbitals and, potentially, alter the dynamics associated with the MLCT state(s). Warnmark and co-workers have pioneered this approach by replacing the bidentate and tridentate polypyridyl ligands with $\mathrm{N}$-heterocyclic carbenes $(\mathrm{NHCs})^{20-23}$. The strongly sigmaelectron donating nature of the carbene-based ligands does in fact result in dramatic increases in MLCT lifetimes due to significant destabilization of the high-spin $\left({ }^{5} \mathrm{~T}_{2}\right)$ state. ${ }^{23,24}$ Complementary approaches include stabilizing the MLCT states by using strongly pi-accepting ligands ${ }^{25}$ or the use 
of sterics which Damrauer and co-workers have successfully employed to increase the lifetime of the ${ }^{5}$ MLCT lifetime of a high-spin Fe(II)-terpyridine complex ${ }^{26,27}$.

More subtle changes in the coordination sphere have also been observed to give rise to unexpected perturbations to the excited-state dynamics of $\mathrm{Fe}$ (II) polypyridyls. One of us (McCusker) recently reported the synthesis, structure, and fundamental photophysics of a new class of $\mathrm{Fe}(\mathrm{II})$ chromophores in which the basic terpyridine motif was modified by the incorporation of a $\mathrm{C}=\mathrm{O}$ group between the $\mathrm{C}-\mathrm{C}$ links of the pyridyl rings. ${ }^{28}$ This new complex $\left[\mathrm{Fe}(\mathrm{dcpp})_{2}\right]^{2+}$ (where depp is di(carboxypyridyl)pyridine) - exhibited a number of structural and dynamic features quite distinct from its polypyridyl cousins $\left[\mathrm{Fe}(\mathrm{bpy})_{3}\right]^{2+}$ and $\left[\mathrm{Fe}(\text { terpy })_{2}\right]^{2+}($ Figure 1). The primary coordination sphere of this compound is a near-perfect octahedron due to the sixmembered metallocycle that is formed upon binding (as opposed to the 5-membered ring that results upon ligation of both bpy and terpy). More surprising was the excited-state. With regard to the compound's photo-induced properties, the time constant for ground-state recovery in fluid $\mathrm{CH}_{3} \mathrm{CN}$ solution was measured to be $280 \pm 10 \mathrm{ps}$, significantly shorter than that of $\left[\mathrm{Fe}(\mathrm{bpy})_{3}\right]^{2+}$ $(960 \pm 20 \mathrm{ps})$ and $\left[\mathrm{Fe}(\text { terpy })_{2}\right]^{2+}(5.35 \pm 0.15 \mathrm{~ns})$ under identical conditions. ${ }^{28}$

The shorter lifetime coupled with data indicating that dcpp presents a significantly stronger ligand-field to Fe(II) than bpy raised a question as to whether this system was the first example of a six-coordinate all-polypyridyl Fe(II) complex whose ligand-field strength pushed the system past the ${ }^{3} \mathrm{~T}_{1} / 5 \mathrm{~T}_{2}$ crossing point in the Tanabe-Sugano diagram, i.e., a pseudo-octahedral polypyridyl compound whose lowest-energy excited state was not the ${ }^{5} \mathrm{~T}_{2}$, but rather the intermediate ${ }^{3} \mathrm{~T}_{1}$ state. The data available at the time of this earlier report were insufficient to 

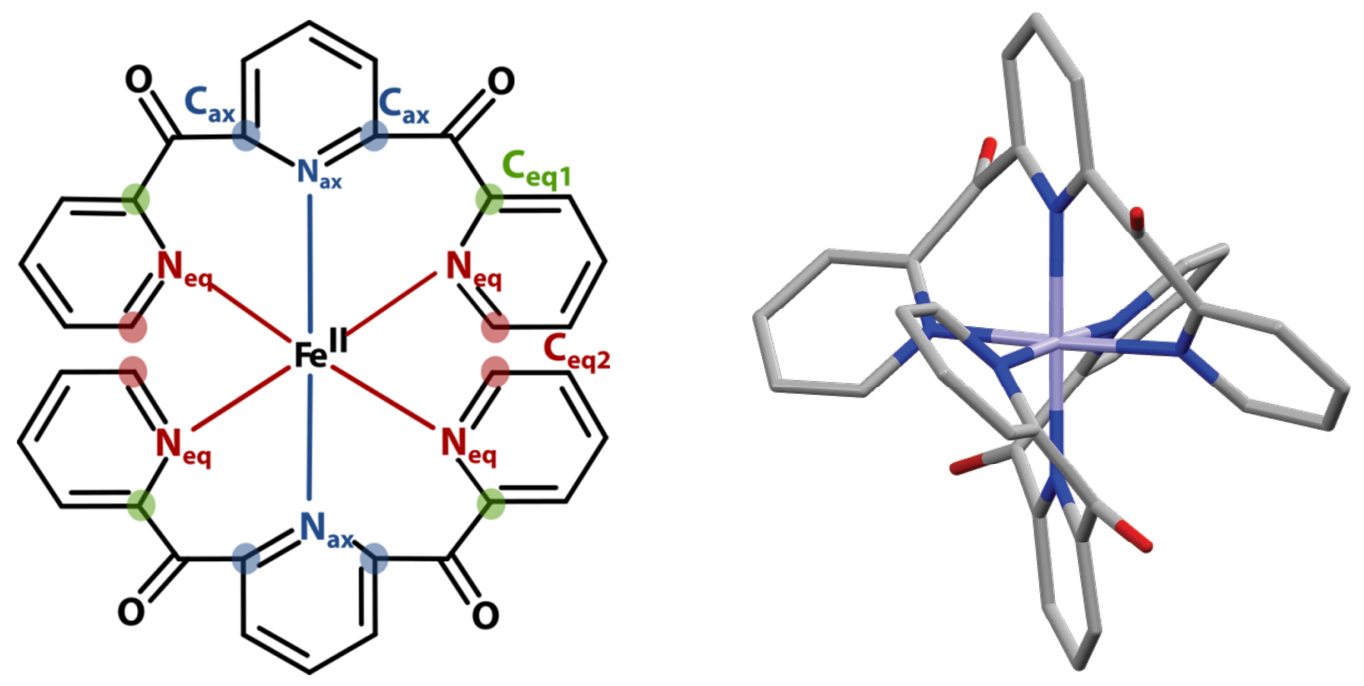

Figure 1. Left: Structural formula of $\left[\mathrm{Fe}(\mathrm{dcpp})_{2}\right]^{+}$, the nitrogen atoms constituting the first coordination shell around $F e$ are grouped into axial $N_{a x}$ and equatorial $N_{\text {eq }}$, the carbon atoms of the second coordination shell into $C_{a x}, C_{e q 1}$ and $C_{e q 2}$. Right: 3-D structure of $\left[\mathrm{Fe}(d c p p)_{2}\right]^{2+}$ obtained from the single-crystal $x$-ray structure reported in ${ }^{28}$. (H atoms omitted for clarity).

differentiate between these two possibilities. Indeed, this ambiguity underscores a fundamental problem that arises when studying the photophysics of the vast majority of first-row metal complexes. Whereas the energetics of charge-transfer states are usually quite easily determined either through emission spectroscopy or electrochemistry, determining the nature and identity of ligand-field excited states can be exceedingly difficult. With rare exceptions (e.g., the ${ }^{2} \mathrm{E}$ state of $\mathrm{Cr}(\mathrm{III})$ complexes), ligand-field excited states are usually non-emissive even at low temperature. This is certainly the case for a ${ }^{5} \mathrm{~T}_{2}$ state, whose radiative coupling to the ${ }^{1} \mathrm{~A}_{1}$ state is virtually zero due to the $\Delta \mathrm{S}=2$ difference between the two states. Electrochemistry is likewise not useful in this regard: ligand-field excited states are not redox in nature and therefore cannot be simulated in a manner similar to charge-transfer states. Finally, with the exception of spin-crossover systems in which the lowest-energy excited state can be accessed either with temperature or through simple 
chemical modifications of the ligand ${ }^{29}$, data from traditional time-resolved optical measurements are generally not diagnostic for the identity of any specific excited state.

With this report, we will show that the combined application of various time-resolved x-ray spectroscopies can succeed in identifying the exact nature of a ligand-field excited state where other methods cannot. Specifically, we have exploited ultrafast x-ray absorption spectroscopy (XAS) and x-ray emission spectroscopy (XES) to meticulously characterize both the geometry and spin of the lowest-energy excited state of $\left[\mathrm{Fe}(\mathrm{dcpp})_{2}\right]^{2+}$. In addition to resolving ligand-field theory questions about this specific compound, we will demonstrate the power of these methods to not only determine the geometric structures of excited states, but to provide insights into the electronic structures that are difficult if not impossible to acquire by other means.

\section{EXPERIMENTAL AND THEORETICAL METHODOLOGY}

Time resolved XAS and XES have been measured at beamline 7ID-D of the Advanced Photon Source at Argonne National Laboratory. The experimental setup has been described previously. ${ }^{30}$ The APS storage ring was operated in 24 bunch mode with an average ring current of $102 \mathrm{~mA}$ in top-up mode. ${ }^{30}$ The laser system, synchronized to the storage ring, generated $10 \mathrm{ps}$ pulses at $\mathrm{MHz}$ repetition rates. $\mathrm{x}$-rays were monochromatized to $\Delta \mathrm{E} / \mathrm{E}=5.4 \times 10^{-5}$ with a doublecrystal diamond (111) monochromator ${ }^{31}$. The sample consisted of a $\sim 10 \mathrm{mM}$ solution of $\left[\mathrm{Fe}(\mathrm{dcpp})_{2}\right]^{2+}$ in $\mathrm{CH}_{3} \mathrm{CN}$ flown through a sapphire nozzle with rectangular $0.1 \mathrm{~mm} \times 6 \mathrm{~mm}$ orifice, which created a $100 \mu \mathrm{m}$ thick flat sheet liquid jet. The liquid jet was tilted to about $45^{\circ}$ with respect to the x-ray propagation direction, allowing a quasi-simultaneous measurement of XES and XAS spectra, i.e. at the front and backside of the liquid jet at $90^{\circ}$ in the vertical plane parallel to the $\mathrm{x}$ ray polarization direction. In order to reduce the amount of sample required, efforts were made to minimize the necessary sample volume to around $20 \mathrm{~mL}$ by employing a peristaltic pump to 
circulate the solution. Evaporation of $\mathrm{CH}_{3} \mathrm{CN}$ was largely suppressed by i) fully enclosing the sample environment, and ii) cooling the sample reservoir by placing it in a chilled water container. Furthermore, a second automated and remote-controlled pump was set up to refill the sample with solvent, allowing frequent (about once per hour) injections of small quantities (on the order of 1 $\mathrm{mL}$ ) without entering the experimental hutch and disturbing the data acquisition.

XAS spectra were measured by scanning the incident x-ray energy from 7.08 to $7.60 \mathrm{keV}$ and measuring the total fluorescence yield (TFY) with a gated scintillator coupled to a photomultiplier tube (S/PMT). The XANES part of the recorded XAS can be found in Figure 2. The laser repetition rate was set to $1.304 \mathrm{MHz}$, i.e. the fifth subharmonic of the x-ray repetition rate of 6.52 MHz. The laser power was set to $1.5 \mathrm{~W}$ exciting the sample with a pulse energy of $1.15 \mu \mathrm{J}$. The lifetime of the excited state was determined by measuring the transient intensity at the strong B-feature of the XANES spectrum while scanning the laser-X-ray delay (Fig. 3). K $\alpha_{1}$ XES (Fig. 4) was measured at equivalent laser excitation conditions with a Johann type ${ }^{32}$ scanning XES spectrometer employing a $100 \mathrm{~cm}$ radius spherically bent $\mathrm{Ge}(440)$ analyzer crystal, which focused the monochromatized fluorescence photons onto a second S/PMT. Full XES spectra were obtained by scanning the Bragg angle over the corresponding range. Reference XES spectra were collected on the powder samples as described previously. ${ }^{8}$ The spectra were normalized by the incident $\mathrm{x}$ ray flux and further background subtracted by setting the high energy tail of the spectrum to zero. The areas of all spectra are normalized to unity to facilitate a comparison between the sample and the reference measurements. Furthermore, reference spectra are arbitrarily shifted as the sample plane of the reference powder was slightly different than the one of the liquid jet.

In a second measurement campaign, K $\beta$ XES (Fig. 5) were obtained with a von Hamos spectrometer ${ }^{33}$ employing a $25 \mathrm{~cm}$ radius cylindrically bent $\mathrm{Si}(531)$ analyzer crystal dispersing 
the spectra onto a gated ${ }^{34}$ Pilatus $100 \mathrm{k}$ detector. Here, the laser repetition rate was set to 0.931 $\mathrm{MHz}$ (the $7^{\text {th }}$ subharmonic of the $6.52 \mathrm{MHz}$ x-ray repetition rate). Owing to the slightly larger laser spot size on the sample, a higher optical laser pulse energy of $2.7 \mu \mathrm{J}$ (corresponding to $2.5 \mathrm{~W}$ ) was chosen in order to match the amplitude of the transient signal (normalized to the absorption edgejump) edge-jump normalized transient signal strength of the first measurement campaign (simultaneous XAS and $\mathrm{K} \alpha_{1} \mathrm{XES}$ ) and ensure the creation of an identical excited state fraction. The full spectra were obtained by selecting a region of interest of the detector and integrating the signal perpendicular to the dispersive axis of the spectrometer. The total area underneath all emission lines are normalized to unity; normalization to the incident x-ray flux is not needed, as the x-ray emission over the full spectral width is acquired within each x-ray pulse.

The structural optimizations for singlet, triplet and quintet spin states of $\left[\mathrm{Fe}(\mathrm{dcpp})_{2}\right]^{2+}$ were done employing the B3LYP functional ${ }^{35-38}$ and Grimme's D2 dispersion correction $^{39}$. An SDD effective core potential and associated basis $\operatorname{set}^{40}$ was utilized for Fe along with $6-311 \mathrm{G}^{*}$ basis $\operatorname{set}^{41-43}$ for all other atoms $(\mathrm{C}, \mathrm{H}, \mathrm{O}, \mathrm{N})$. Geometry optimizations were performed with polarizable continuum model $(\mathrm{PCM})^{44}$ for water as a solvent. The computational approach was chosen based on our previous work, as it provided for reliable optimized structures and spin-state energetics for $\left[\mathrm{Fe}(\text { terpy })_{2}\right]^{2+}$ and $\left[\mathrm{Fe}(\mathrm{dcpp})_{2}\right]^{2+}$ based compounds. ${ }^{45,46}$ The local minima on the potential energy surface were confirmed with the vibrational frequency analysis for all the equilibrium structures. Cartesian coordinates of all optimized complexes are provided in a xyz file format as Supplemental Information. These calculations were carried out using Gaussian 09 software package. ${ }^{47}$

We carried out additional geometry optimizations utilizing the BP86 $6^{48,49}$ exchangecorrelation functional in combination with the TZP Slater atomic basis set, as implemented in the ADF2013 program package. ${ }^{50-52}$ In these calculations, we constrained the occupation of molecular 
orbitals by $\mathrm{D}_{2}$ point group symmetry for the three components of the ${ }^{5} \mathrm{~T}_{2}$ manifold $\left({ }^{5} \mathrm{~B}_{2},{ }^{5} \mathrm{~A}\right.$, and $\left.{ }^{5} \mathrm{~B}_{3}\right)$.

\section{RESULTS AND DISCUSSION}

The iron K-edge XANES spectra of $\left[\mathrm{Fe}(\mathrm{dcpp})_{2}\right]^{2+}$ in $\mathrm{CH}_{3} \mathrm{CN}$ with and without laser excitation are shown in Figure 2. The most prominent features are labeled A-E; in terms of the qualitative spectral features, transient changes in the XANES spectra are almost identical to those observed following photoexcitation of $\left[\mathrm{Fe}(\mathrm{bpy})_{3}\right]^{2+6}$ and $\left[\mathrm{Fe}(\text { terpy })_{2}\right]^{2+}{ }^{9-11}$. The spectral range labeled A is assigned to the so-called pre-edge region where bound-bound transition to unoccupied molecular orbitals can be found. These transitions correspond to formally dipole-forbidden $1 s \rightarrow 3 d$ transitions, of both $t_{2 g}$ and $e_{g}{ }^{*}$ character. Spectral changes in this region reflect directly the change in occupancy of different $3 d$ metal orbitals due to spin transition. In fact the final states of these weak resonances are the same as in case of transition metal L-edge spectra, however in the latter case the XAS spectra are dominated by dipole-allowed $2 p \rightarrow 3 d$ transitions and therefore bearing much higher sensitivity to the occupancy of $3 d\left(\mathrm{t}_{2 \mathrm{~g}}\right)$ and $3 d\left(\mathrm{e}_{\mathrm{g}}{ }^{*}\right)$ orbitals as has been reported earlier for similar Fe(II)-based complexes. ${ }^{53,54}$ The other spectral features visible in the XANES spectrum in Fig. 2 correspond to multiple scattering resonances in the vicinity of the ionization potential and therefore they are quite sensitive to the overall molecular structure of the complex, similarly to other K-edge spectra of Fe complexes ${ }^{6,9,55}$. However, none of the spectral features in the XAS spectrum allows for an unambiguous determination of the spin multiplicity of the metal, which is one of the primary goals of our study. The temporal decay of the B feature together with a fit is shown in Figure 3. The fit is a convolution of a Gaussian-broadened step function with an exponential decay and results in a $(77 \pm 3)$ ps risetime reflecting the $\mathrm{x}$-ray pulse duration and a (272 \pm 4$)$ ps decay, in excellent agreement with the known lifetime of the lowest-energy excited 
state of $\left[\mathrm{Fe}(\mathrm{dcpp})_{2}\right]^{2+}$ in $\mathrm{CH}_{3} \mathrm{CN}$ solution ${ }^{28}$. This lifetime is significantly shorter than that observed for $\left[\mathrm{Fe}(\mathrm{bpy})_{3}\right]^{2+}\left(0.96 \mathrm{~ns}\right.$ in $\left.\mathrm{CH}_{3} \mathrm{CN}^{28}\right)$ and $\left[\mathrm{Fe}(\text { terpy })_{2}\right]^{2+}\left(5.35 \mathrm{~ns}\right.$ in $\left.\mathrm{CH}_{3} \mathrm{CN}^{28}\right)$ under identical experimental conditions. As mentioned above, this observation coupled with the increased ligandfield strength imparted by the dcpp ligand relative to both bpy and terpy prompted consideration that the lowest-energy excited state of $\left[\mathrm{Fe}(\mathrm{dcpp})_{2}\right]^{2+}$ was the ${ }^{3} \mathrm{~T}_{1}$ state as opposed to the ${ }^{5} \mathrm{~T}_{2}$ state characteristic of other Fe(II) polypyridyl complexes.

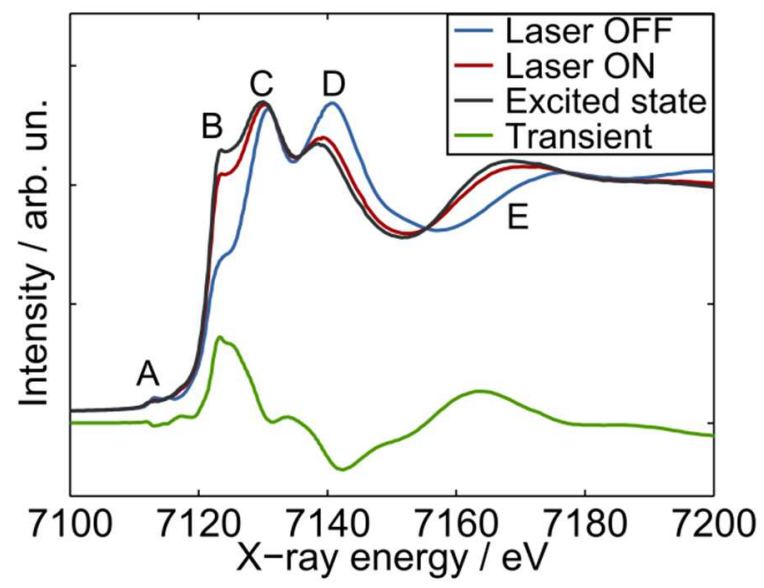

Figure 2. The XANES region of the K-edge spectra of the ${ }^{1} A_{1}$ ground state $\left[\mathrm{Fe}(\mathrm{dcpp})_{2}\right]\left(\mathrm{PF}_{6}\right)_{2}$ in $\mathrm{CH}_{3} \mathrm{CN}$ solution (blue), $\sim 50$ ps after $532 \mathrm{~nm}$ laser excitation (red), the transient difference spectrum (green), and of the compound's lowest-energy excited state assuming an excited-state fraction of $=78 \%$ has been produced (grey).

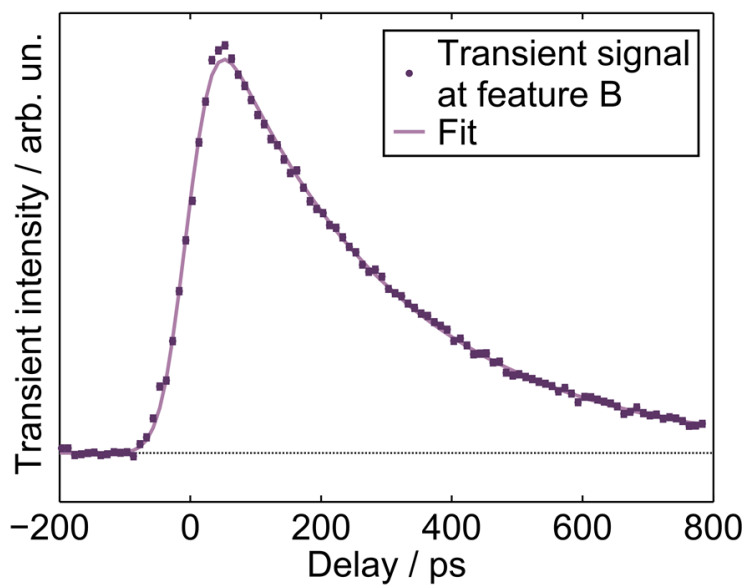

Figure 3. Kinetics trace for $\left[\mathrm{Fe}(\mathrm{dcpp})_{2}\right]\left(\mathrm{PF}_{6}\right)_{2}$ in $\mathrm{CH}_{3} \mathrm{CN}$ solution at the $\mathrm{B}$ feature (7123 eV) following ${ }^{1} A_{1} \rightarrow{ }^{1} M L C T$ excitation. The data can be described by a single exponential kinetic model with $\tau_{o b s}=(272 \pm 4)$ ps. 
To address this unresolved question, we have measured $\mathrm{K} \alpha_{1} \mathrm{XES}$ in analogy to the measurements on $\left[\mathrm{Fe}(\text { bpy })_{3}\right]^{2+7,56,57}$ and $\left[\mathrm{Fe}(\text { terpy })_{2}\right]^{2+9}$ in order to determine the spin of the excited-state being sampled in the ground-state recovery dynamics of $\left[\mathrm{Fe}(\mathrm{dcpp})_{2}\right]^{2+}$. The spectra of the GS, about $50 \mathrm{ps}$ after laser excitation and their respective difference, as well as the
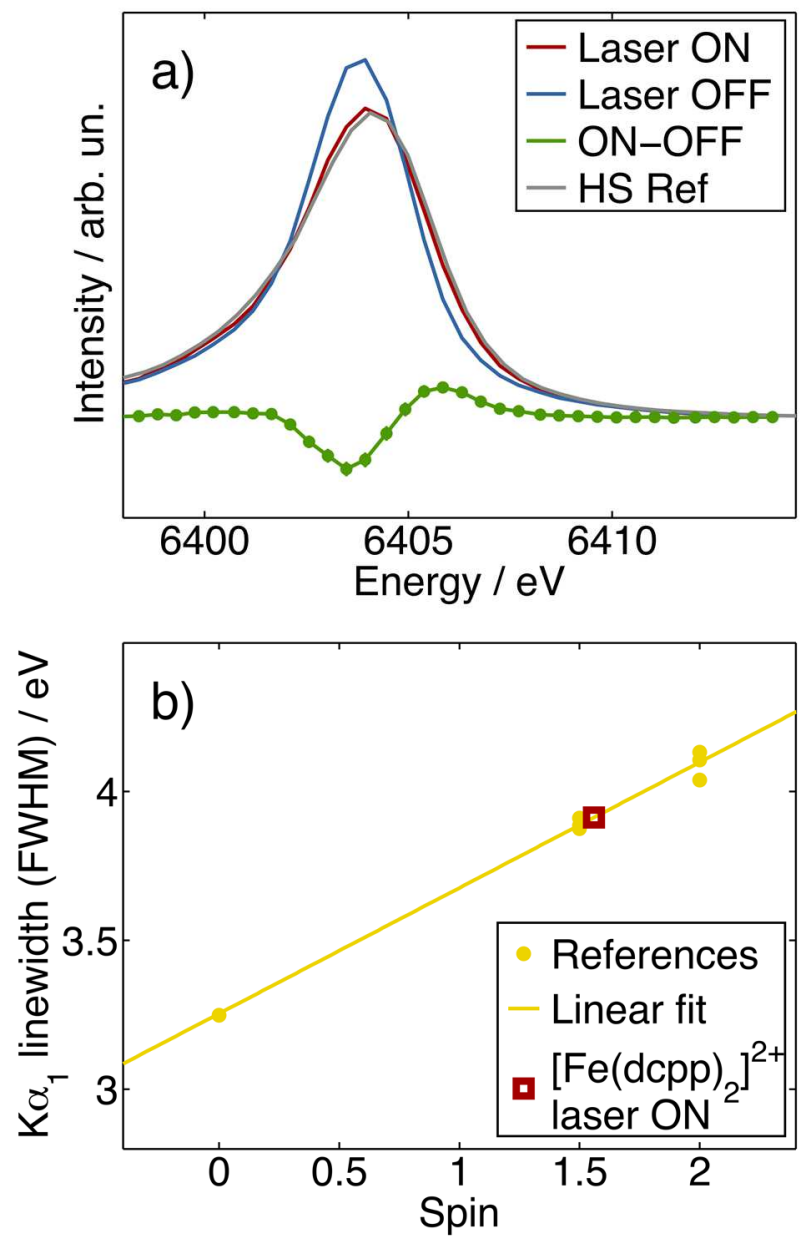

Figure 4. a) $\mathrm{K} \alpha_{1} \mathrm{XES}$ spectra of the ground state of $\left[\mathrm{Fe}(\mathrm{dcpp})_{2}\right]^{2+}$ (blue), $50 \mathrm{ps}$ after laser excitation (red), and the excited-state/ground-state transient difference (green). The corresponding spectrum of a standard which possesses a high-spin, $S=2$ ground state, is also

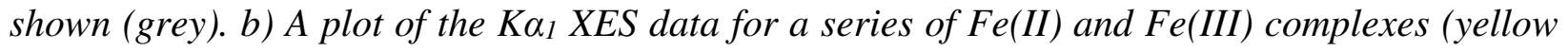
points), revealing an approximately linear correlation between spin-state and spectral line width.. The spectrum acquired subsequent to photoexcitation of $\left[\mathrm{Fe}(\mathrm{dcpp})_{2}\right]^{2+}$ corresponds to an average spin of $S_{d c p p, L O N}=1.56$, a value consistent with sampling a $S=2$ excited state with a $f=78 \%$ excited-state fraction.

spectrum of a high-spin $(S=2)$ reference complex can be seen in Figure $4 a$. It can be seen that the laser $\mathrm{ON}$ spectrum is virtually identical to the $\mathrm{S}=2$ reference spectrum, an indication that the 
excited state for $\left[\mathrm{Fe}(\mathrm{dcpp})_{2}\right]^{2+}$ is likely $\mathrm{S}=2$ in character. A more detailed assessment of the average spin-state of the photo-excited ensemble is facilitated by the approximately linear relation that exists between the number of unpaired $3 d$ electrons and the $\mathrm{K} \alpha_{1}$ linewidth $^{58,59}$. The line shape of the ground- and photo-induced excited states of $\left[\mathrm{Fe}(\mathrm{dcpp})_{2}\right]^{2+}$ along with a series of static references having $S=3 / 2$ and $S=2$ have been analyzed based on based on the approach by Vankó et al. ${ }^{58}$ This relationship is highlighted in Figure $4 \mathrm{~b}$, which shows a plot of the $\mathrm{K} \alpha_{1}$ line width as a function of $\mathrm{S}$ for a series of $\mathrm{Fe}(\mathrm{II})$ and $\mathrm{Fe}(\mathrm{III})$ complexes. The experimentally determined line width of the photoexcited sample of $\left[\mathrm{Fe}(\mathrm{dcpp})_{2}\right]^{2+}$ corresponds to a spin of $\mathrm{S}=1.56$, however, this value represents a superposition of the excited state being sampled as well as any residual ground state not upconverted upon excitation. The fraction of sample that is actually excited and sampled will vary depending on pulse power, pump-probe cross-section, and the molar absorptivity of the absorption feature among other factors, and in principle can range from 0 to $100 \%$. Assuming that only a single excited state is being sampled following photoexcitation, we can use the excitation fraction as a weighting factor and describe the spin-state value obtained from the correlation in Figure $4 \mathrm{~b}$ as

$$
\mathrm{S}_{\mathrm{exp}}=(1-f) \mathrm{S}_{\mathrm{GS}}+f \mathrm{~S}_{\mathrm{ES}}
$$

where $\mathrm{S}_{\mathrm{GS}}$ and $\mathrm{S}_{\mathrm{ES}}$ are the spin values corresponding to the ground and excited states, respectively, and $f$ is the excitation fraction. For $\left[\mathrm{Fe}(\mathrm{dcpp})_{2}\right]^{2+}, \mathrm{S}_{\mathrm{GS}}=0$ and $\mathrm{S}_{\exp }=1.56$; since the excitation fraction cannot be larger than 1 (i.e., you cannot produce more excited state than you have ground state to begin with), a value of $S_{\exp }=1.56$ in eq. 1 effectively rules out an isolated ${ }^{3} T_{1}$ term as the lowest energy excited state of $\left[\mathrm{Fe}(\mathrm{dcpp})_{2}\right]^{2+}$. The experimental data can be interpreted in terms of a ${ }^{5} \mathrm{~T}_{2}$ excited state for $\left[\mathrm{Fe}(\mathrm{dcpp})_{2}\right]^{2+}$ assuming $f=0.78$, i.e., photoexcitation results in $78 \%$ of the sample being converted to the excited state. This represents a large but plausible excitation cross- 
section given that the molar absorptivity at the excitation wavelength $(532 \mathrm{~nm})$ is on the order of $10^{3} \mathrm{M}^{-1} \mathrm{~cm}^{-1}$.

Despite the reasonableness of the above analysis, the $\mathrm{K} \alpha_{1}$ measurements cannot completely exclude a contribution of a second excited state species (e.g., a thermally accessible ${ }^{3} \mathrm{~T}_{1}$ state and/or extensive mixing between the ${ }^{5} \mathrm{~T}_{2}$ and ${ }^{3} \mathrm{~T}_{1}$ terms). To verify that the $\mathrm{S}=2$ state is the only excited state contributing to the $\mathrm{K} \alpha_{1}$ signal, we therefore measured the $\mathrm{K} \beta_{1,3} \mathrm{x}$-ray emission spectrum of $\left[\mathrm{Fe}(\mathrm{dcpp})_{2}\right]^{2+}$ due to the distinct features it exhibits as a function of spin-state in iron complexes ${ }^{8}$. The $\mathrm{K} \beta_{1,3} \mathrm{XES}$ data we acquired are shown in Figure 5a, together with spectra for the ground states of low-spin ( $\mathrm{S}=0)$ and high-spin $(\mathrm{S}=2)$ complexes, which have previously been measured by $\mathrm{W}$. Zhang et $a l .{ }^{8}$, for comparison. The main feature of the laser ON spectrum exhibits a blue shift compared to the GS spectrum and exhibits a spectral profile that is virtually identical to the $S=2$ reference spectrum. Moreover, the transient difference spectrum for $\left[\mathrm{Fe}(\mathrm{dcpp})_{2}\right]^{2+}$ (Figure $\left.5 \mathrm{~b}\right)$ is wholly consistent with what has previously been observed for other compounds possessing an isolated ${ }^{5} \mathrm{~T}_{2}$ term as their lower energy excited states, with the amplitude and other features reminiscent of the typical fingerprints of the singlet-quintet difference spectrum. In contrast, there are distinct qualitative disparities between the data for $\left[\mathrm{Fe}(\mathrm{dcpp})_{2}\right]^{2+}$ and the expected singlettriplet difference spectrum. We have quantified this result further by assessing the fits of the data on $\left[\mathrm{Fe}(\mathrm{dcpp})_{2}\right]^{2+}$ in terms of their consistency with a triplet versus quintet excited state. We have calculated the transient differences spectra for linear combinations of triplet-singlet (grey in Fig. 5b) and quintet-singlet (yellow in Fig. 5b) differences for each contributing between $0 \%$ and $100 \%$. The reduced square deviation $\chi_{r}^{2}$ of this superposition and the measured difference is shown in the contour plot in Figure 5c. The minimum $\chi_{\mathrm{r}}^{2}$, corresponding to the best agreement of the reference difference and the experimental data, was obtained for a quintet contribution of $f_{\mathrm{Q}}=72 \%$ and a 
triplet contribution of $f_{\mathrm{T}}=0 \%$, a result that is in excellent agreement with the result obtained from the analysis of the Ka XES data.

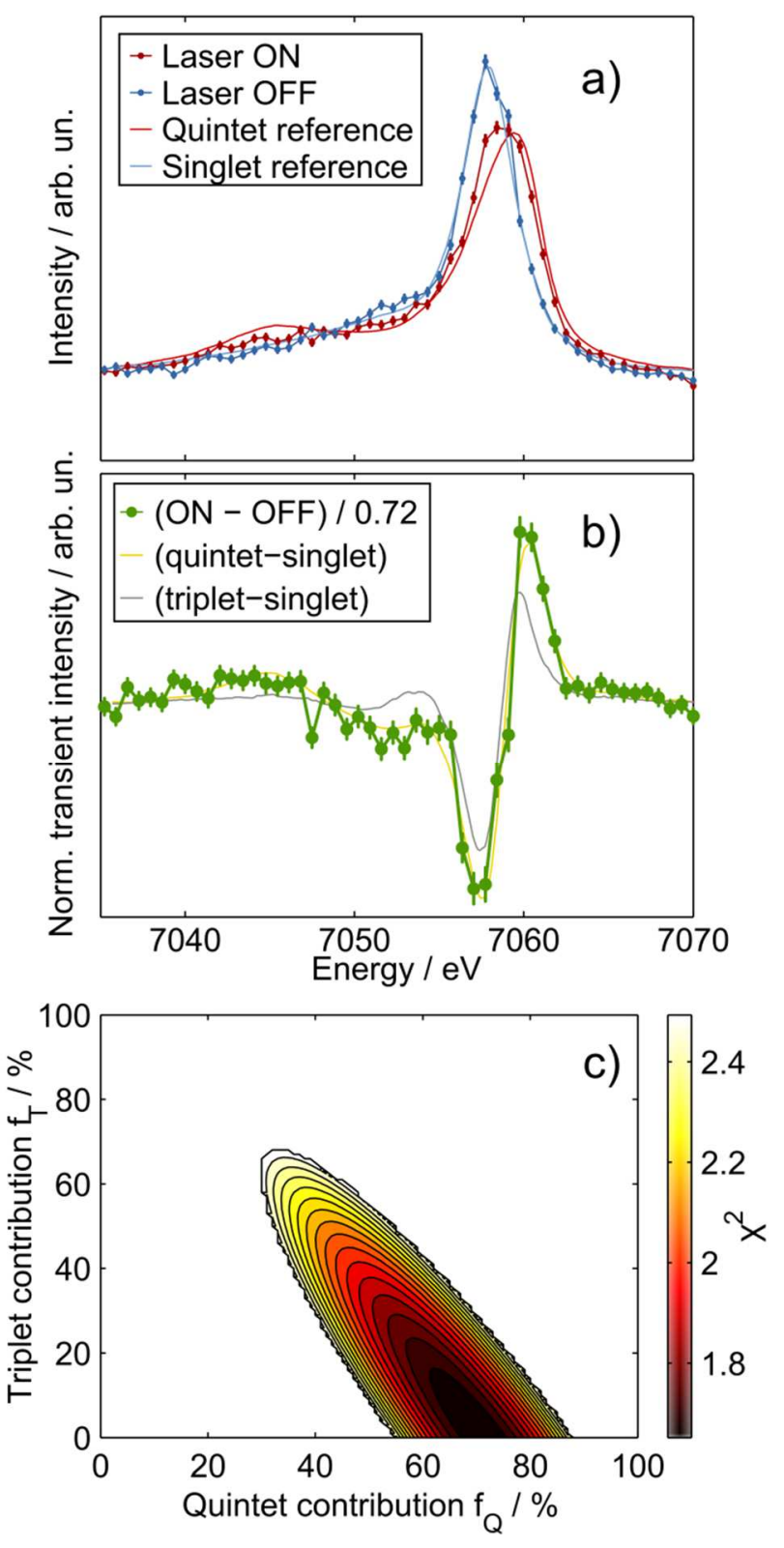

Figure 5. a) K $\beta \mathrm{XES}$ spectra of $\left[\mathrm{Fe}(\mathrm{dcpp})_{2}\right]^{2+}$ in ground state (blue) and 50 ps after laser excitation (red); spectra corresponding to model complexes having $S=0$ and $S=2$ are also shown. $b$ ) Normalized difference spectra between the ground and excited states of $\left[\mathrm{Fe}(\mathrm{dcpp})_{2}\right]^{2}$ (green) compared to those corresponding to excited states having $S=1$ (grey) and $S=2$ (yellow) (all reference spectra shown here are obtained from ref $\left.^{8}\right) . c$ ) $\chi_{r}^{2}$ contour plot of the transient K $\beta$ XES fit as a function of triplet-singlet and quintet-singlet contributions. The minimum is observed at $0 \%$ triplet and $72 \%$ quintet, consistent with $\left[\mathrm{Fe}(\mathrm{dcpp})_{2}\right]^{2+}$ having an (isolated) $S=2$ lowest-energy excited state. 
Having established the ${ }^{5} \mathrm{~T}_{2}$ state as the lowest energy excited state of $\left[\mathrm{Fe}(\mathrm{dcpp})_{2}\right]^{2+}$, we turned our attention to characterizing the molecular structure changes accompanying the LS-HS conversion by analyzing the EXAFS part of the XAS. In the first step, the XAS of the pure excited state spectrum $\mu_{\mathrm{ES}}$ is reconstructed from the laser ON spectrum $\mu_{\mathrm{LON}}$ and laser OFF spectrum $\mu_{\mathrm{LOFF}}$ using the excited state fraction $f$ determined from the XES measurements via

$$
\mu_{\mathrm{ES}}=\mu_{\mathrm{LOFF}}+(1 / \mathrm{f}) *\left(\mu_{\mathrm{ON}}-\mu_{\mathrm{LOFF}}\right)
$$

where the laser-off spectrum corresponds to the ground-state spectrum, i.e., $\mu_{\mathrm{GS}}=\mu_{\mathrm{LOFF}}$. The atomic background is then subtracted and the resultant spectrum normalized to a unitary K-edge step height, yielding the EXAFS spectra $\chi_{\mathrm{GS}}(\mathrm{E})$ and $\chi_{\mathrm{ES}}(\mathrm{E})$ of the GS and ES, respectively, using ATHENA from the IFEFFIT toolbox ${ }^{60}$. The energy axis can be converted to a photo-electron wave-number $\mathrm{k}$ axis; to enhance the visibility of the EXAFS features at higher energies, the spectra can be additionally $\mathrm{k}^{2}$ weighted as shown in Figures $6 \mathrm{a}$ and $6 \mathrm{~b}$. Fourier-transformation (FT) of the EXAFS spectra from k- to R-space results in pseudo-radial distribution functions (Figures $6 \mathrm{c}$ and 6d) ${ }^{61}$. EXAFS spectra for $\left[\mathrm{Fe}(\mathrm{dcpp})_{2}\right]^{2+}$ are shown in Figure 6 . They have been modeled with FEFF8 ${ }^{62}$ using the DFT calculated ${ }^{1} \mathrm{~A}_{1}$ structure for the GS and a possible triplet ${ }^{3} \mathrm{~T}_{1}$ and quintet ${ }^{5} \mathrm{~T}_{2}$ structure for the excited state. These have been used as starting guesses in fitting the EXAFS spectra using the Artemis software, which is also part of IFEFFIT. In the GS fit, Fe- $\mathrm{N}_{\mathrm{ax}}, \mathrm{Fe}-\mathrm{N}_{\mathrm{eq}}$, $\mathrm{Fe}-\mathrm{C}_{\mathrm{ax}}, \mathrm{Fe}-\mathrm{C}_{\mathrm{eq}}$ and $\mathrm{Fe}-\mathrm{C}_{\mathrm{eq} 2}$ bond lengths as well as non-structural parameters such as an energy shift, amplitude reduction factor and Debye-Waller factors are optimized. In the ES fit, the nonstructural parameters are fixed to those of the GS and only the five bond-lengths are fitted (further details on the EXAFS fit can be found in the SI). For the excited state fit, both the ${ }^{3} \mathrm{~T}_{1}$ and ${ }^{5} \mathrm{~T}_{2}$ structures have been used as starting guesses to facilitate an unbiased structure determination, and both fits converged to the same result. 

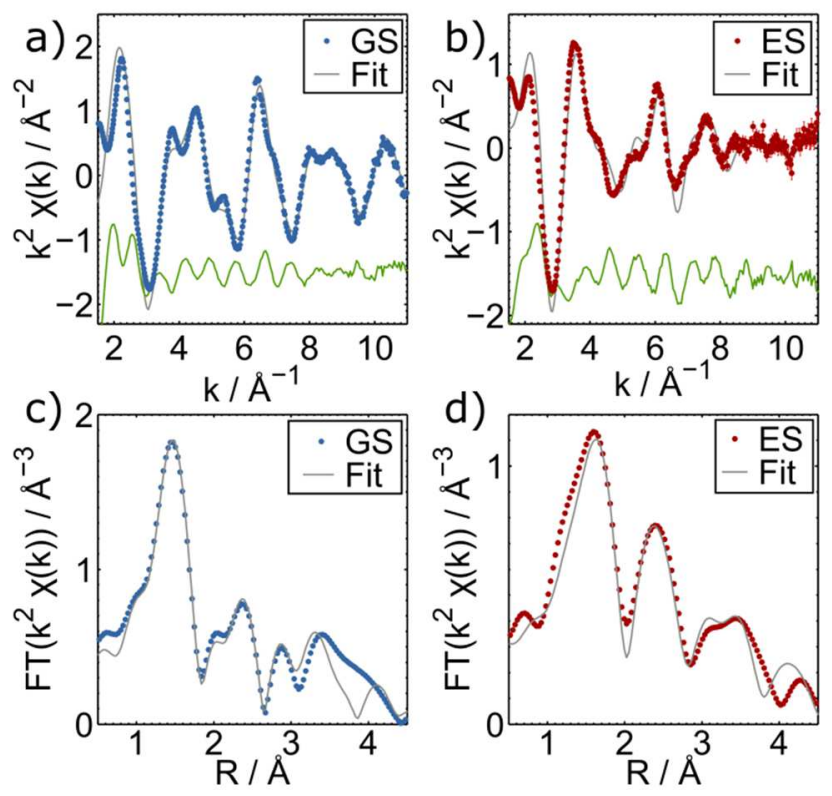

Figure 6. a) Ground-state and b) Excited-state $k^{2}$ weighted EXAFS spectra of $\left[\mathrm{Fe}(\mathrm{dcpp})_{2}\right]^{2+}$ in $k$ space. c) Ground-state and d) Excited-state EXAFS spectra in R-space. For the $k^{2}$-weighted spectra, the residuals of the fit are plotted in green.

The obtained GS and ES Fe-N and Fe-C bond lengths as well as those of the three DFT structural models are summarized in Table 1. The GS structure from EXAFS is in good agreement with experiment as well as the DFT geometry-optimized structure, with only small discrepancies in the bond lengths being observed. The typical structural changes associated with a low-spin to high-spin conversion in $\mathrm{Fe}$ (II) are evident, with an average $\mathrm{Fe}-\mathrm{N}$ bond elongation of $\sim 0.18 \AA$ due to the population of the $\mathrm{e}_{\mathrm{g}}{ }^{*} \sigma$-antibonding orbitals in the $\left(\mathrm{t}_{2 \mathrm{~g}}\right)^{4}\left(\mathrm{e}_{\mathrm{g}}{ }^{*}\right)^{2}$ configuration that characterizes the ${ }^{5} \mathrm{~T}_{2}$ state. In contrast, an $\mathrm{S}=1$ state that derives from a $\left(\mathrm{t}_{2 \mathrm{~g}}\right)^{5}\left(\mathrm{e}_{\mathrm{g}}{ }^{*}\right)^{1}$ configuration would be expected to exhibit a much smaller average bond elongation, as has been observed in $\left[\mathrm{Co}(\operatorname{terpy})_{2}\right]^{2+}$ with an average Co-N bond elongation of $\sim 0.08 \AA^{63}$. Nevertheless, while the primary coordination sphere for the ground state of $\left[\mathrm{Fe}(\mathrm{dcpp})_{2}\right]^{2+}$ is almost perfectly $\mathrm{O}_{\mathrm{h}}$ in symmetry, the excited-state 
structure exhibits a surprisingly anisotropic distortion with significant differences between the axial $\left(\mathrm{R}\left(\mathrm{Fe}-\mathrm{N}_{\mathrm{ax}}\right)=2.05 \AA\right)$ and equatorial

Table 1. Experimentally determined first and second coordination shell bond lengths of $\left[\mathrm{Fe}(\mathrm{dcpp})_{2}\right]^{2+}$ in its ground state, its excited state, and their respective difference. Bond lengths obtained from $x$-ray crystallography as well as DFT (B3LYP+D2/SDD,6-311G* level of theory) are shown for comparison. The error estimates as estimated standard deviations obtained from ARTEMIS are given in brackets.

\begin{tabular}{|l|l|l|l|l|l|}
\hline & $\begin{array}{l}\mathrm{R}\left(\mathrm{Fe}-\mathrm{N}_{\mathrm{ax}}\right) / \\
\AA\end{array}$ & $\begin{array}{l}\mathrm{R}\left(\mathrm{Fe}-\mathrm{N}_{\mathrm{eq}}\right) / \\
\AA\end{array}$ & $\begin{array}{l}\mathrm{R}\left(\mathrm{Fe}-\mathrm{C}_{\mathrm{ax}}\right) / \\
\AA\end{array}$ & $\begin{array}{l}\mathrm{R}\left(\mathrm{Fe}-\mathrm{C}_{\mathrm{eq} 1}\right) / \\
\AA\end{array}$ & $\begin{array}{l}\mathrm{R}\left(\mathrm{Fe}-\mathrm{C}_{\mathrm{eq}}\right) \\
/ \AA\end{array}$ \\
\hline${ }^{1} \mathrm{~A}_{1}$ from DFT & 2.00 & 2.02 & 2.93 & 2.95 & 2.94 \\
\hline $\begin{array}{l}\text { Ground state } \\
\text { rrom x-ray } \\
\text { cryst. }^{28}\end{array}$ & $1.974(2)$ & $\begin{array}{l}1.985(2) \\
-1.989(2)\end{array}$ & $2.920(5)$ & $2.925(3)$ & $2.931(3)$ \\
\hline $\begin{array}{l}\text { Ground state } \\
\text { from EXAFS }\end{array}$ & $1.96(1)$ & $1.98(1)$ & $2.91(2)$ & $2.92(2)$ & $2.92(2)$ \\
\hline $\begin{array}{l}{ }^{3} \mathrm{~T}_{1} \text { structure } \\
\text { from DFT }\end{array}$ & 1.98 & 2.14 & 2.92 & 3.02 & 3.06 \\
\hline $\begin{array}{l}5 \\
\mathrm{~T}_{2} \text { structure } \\
\text { from DFT }\end{array}$ & 2.16 & 2.17 & 3.07 & 3.08 & 3.06 \\
\hline $\begin{array}{l}\text { Excited state } \\
\text { from EXAFS }\end{array}$ & $2.05(2)$ & $2.21(2)$ & $2.97(4)$ & $3.10(2)$ & $3.07(2)$ \\
\hline Diff. GS-ES & $+0.09(2)$ & $+0.23(2)$ & $+0.06(5)$ & $+0.17(3)$ & $+0.15(3)$ \\
\hline
\end{tabular}

$\left(\mathrm{R}\left(\mathrm{Fe}-\mathrm{N}_{\mathrm{eq}}\right)=2.21 \AA\right)$ bond distances. Nevertheless, this fit result is in contrast to the DFT geometries, which predicts an almost perfectly octahedral structure in the ${ }^{5} \mathrm{~T}_{2}$ state. The reasons for disagreement between the DFT-optimized geometries and experimental data are unclear. With the analyzed k-range from $2.5 \AA^{-1}-10.5 \AA^{-1}$ we cannot observe the Fe- $\mathrm{N}_{\text {ax }}$ and Fe- $\mathrm{N}_{\text {eq }}$ bonds as separate peaks in the pseudo radial distribution functions (Figs 6c and 6d) and resolve their relative bond length difference of $\sim 0.02 \AA$ in the GS. Nevertheless, the bond length changes of the inequivalent Fe-N bonds during the LS-HS transition of $\left[\mathrm{Fe}(\text { terpy })_{2}\right]^{2+9,11}$ and $[\mathrm{Fe}(\mathrm{tpen})]^{2+64}$ have been characterized with a similar k-range and we can analogously use the change in peak width and intensity to quantify the change in symmetry in the first coordination shell of $\left[\mathrm{Fe}(\mathrm{dcpp})_{2}\right]^{2+}$. The increased asymmetry in the ES is reflected in the broadening and strong peak intensity 
decrease, which could otherwise only be explained by a large change in the Debye-Waller factor, although within the $\sim 100$ ps temporal resolution of the measurement the largest part of the ensemble of molecules in the ES have thermalized. To further test the excited state EXAFS fit result we have constraint the geometry to a symmetric one, which leads to a comparably good symmetric fit, but with a significant and almost unreasonable ( 6-fold for the first coordination shell compared to the ground state) increase in the Debye-Waller factors and amplitude reduction factor (see Table S3). Constrained optimizations of $\left[\mathrm{Fe}(\mathrm{dcpp})_{2}\right]^{2+}$ in the ${ }^{5} \mathrm{~T}_{2}$ state with $\mathrm{Fe}-\mathrm{N}_{\mathrm{ax}}$ and Fe- $\mathrm{N}_{\mathrm{eq}}$ bond lengths fixed at $2.05 \AA$ and $2.21 \AA$, respectively, yielded two different structures that are only $4.8 \mathrm{kcal} / \mathrm{mol}$ and $2.6 \mathrm{kcal} / \mathrm{mol}$ higher in energy than the fully optimized ${ }^{5} \mathrm{~T}_{2}$ structure. The two structures differ from each other by orbital occupancy and inter-ligand interactions (natural orbitals showing $\mathrm{d}$ orbital occupation as well as a table with structural parameters for fullyoptimized and constrained-optimized structures can be found in the SI). This suggests that the PES of ${ }^{5} \mathrm{~T}_{2}$ state is flat with respect to the asymmetric distortions along the axial and equatorial $\mathrm{Fe}-\mathrm{N}$ bond lengths. Unlike $\left[\mathrm{Fe}(\text { terpy })_{2}\right]^{2+}$ and $\left[\mathrm{Fe}(\mathrm{bpy})_{3}\right]^{2+}$ complexes, $\left[\mathrm{Fe}(\mathrm{dcpp})_{2}\right]^{2+}$ displays significant inter-ligand interactions between the $\mathrm{CO}$ bridging groups of one dcpp ligand and pyridine moieties of the second dcpp ligand (see Figure 1), calculated C (CO) - N (pyridine) distance is $2.90 \AA$ (2.84$2.87 \AA$ in the crystal structure). It is possible that these inter-ligand interactions affect the structure of the complex in the ES, and that our chosen computational methodology is unable to describe them with sufficient accuracy.

We have also attempted to find fully-optimized asymmetric structures. The pseudooctahedral ligand field of molecules possessing $\mathrm{D}_{2}$ molecular symmetry, as is the $\left[\mathrm{Fe}(\mathrm{dcpp})_{2}\right]^{2+}$ complex, splits the ${ }^{5} \mathrm{~T}_{2}$ state into three components: the ${ }^{5} \mathrm{~B}_{2},{ }^{5} \mathrm{~A}$, and ${ }^{5} \mathrm{~B}_{3}$. Geometry optimizations utilizing the BP86 exchange-correlation functional ${ }^{48,49}$ show that the energy splitting of these states 
is below $50 \mathrm{meV}$ (the lowest being the ${ }^{5} \mathrm{~B}_{3}$ ). Furthermore, while the ${ }^{5} \mathrm{~B}_{2}$ structure reflects an almost completely symmetric FeN6 core, the one of the ${ }^{5} \mathrm{~A}$ and ${ }^{5} \mathrm{~B}_{3}$ exhibits a Fe-N anisotropy of ca. 0.05 $\AA$ and $0.03 \AA$, respectively. These results hint at the existence of an energetically accessible distorted HS structure, even if the theory-predicted anisotropy is significantly smaller than the one obtained from the EXAFS experiment $(0.16 \AA) .{ }^{50-52}$

To further verify the anisotropically distorted excited state we have compared the EXAFS spectra to those of $\left[\mathrm{Fe}(\text { terpy })_{2}\right]^{2+}$ in its ground and excited states (Figure 7). The ground-state EXAFS spectrum for $\left[\mathrm{Fe}(\text { terpy })_{2}\right]^{2+}$ differs significantly from that of $\left[\mathrm{Fe}(\mathrm{dcpp})_{2}\right]^{2+}$, reflecting the distinctly different ground-state structures of the two compounds. Interestingly, the compounds become far more similar in the excited state: the first coordination shell of the excited state of $\left[\mathrm{Fe}(\text { terpy })_{2}\right]^{2+}$ is very similar to that of $\left[\mathrm{Fe}(\mathrm{dcpp})_{2}\right]^{2+}$, with $\mathrm{R}\left(\mathrm{Fe}-\mathrm{N}_{\mathrm{ax}}\right)=2.08 \AA$ and $\mathrm{R}\left(\mathrm{Fe}-\mathrm{N}_{\mathrm{eq}}\right)=$ $2.20 \AA^{9}$ (Figure 7e). This leads to almost identical excited-state EXAFS spectra for the two compounds (Figures 7f). The overall result is therefore rather intriguing: whereas the low-spin to high-spin conversion in $\left[\mathrm{Fe}(\text { terpy })_{2}\right]^{2+}$ is more or less isotropic, the same process in $\left[\mathrm{Fe}(\mathrm{dcpp})_{2}\right]^{2+}$ is very anisotropic. The reasons underlying this difference in behavior is still unclear but likely relates to the greater degree of geometric constraint associated with the terpy ligand (which creates 5-membered rings upon chelation to a metal center) as compared to the more structurally accommodating 6-membered metallocycles that result from dcpp complexation. 

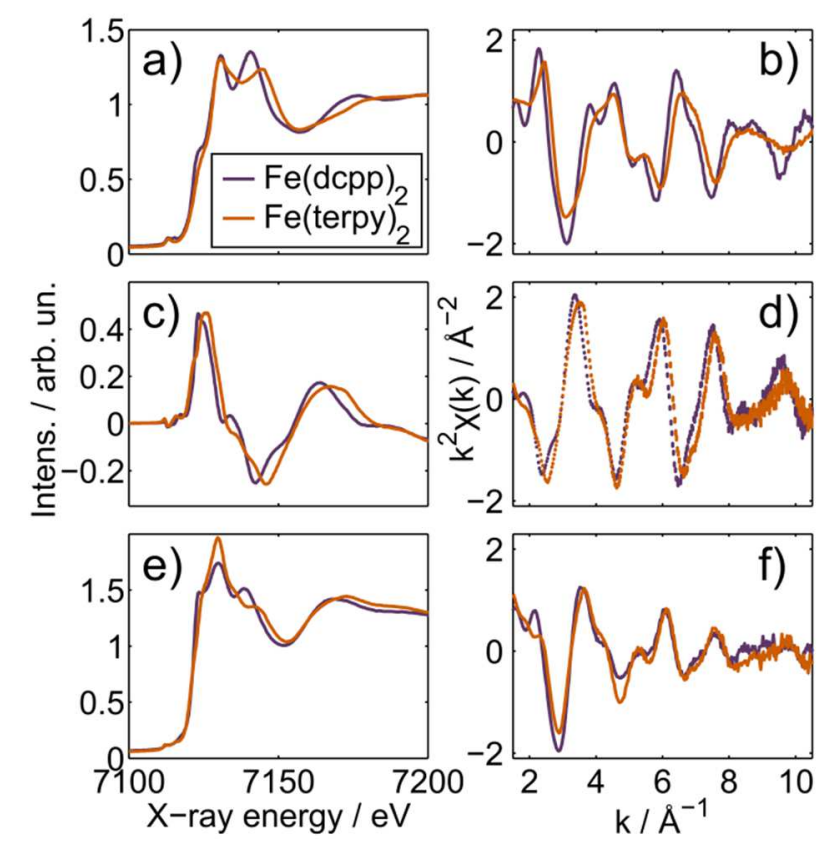

Figure 7. a) Ground-state XANES spectra of $\left[\mathrm{Fe}(\mathrm{dcpp})_{2}\right]^{2+}$ (from this work) and $\left[\mathrm{Fe}(\text { terpy })_{2}\right]^{2+}$ (reproduced from ref 4). b) $k^{2}$-weighted ground-state EXAFS spectra of $\left[\mathrm{Fe}(\mathrm{dcpp})_{2}\right]^{2+}$ and $\left[\mathrm{Fe}(\text { terpy })_{2}\right]^{2+}$. c) Transient XANES spectrum for $\left[\mathrm{Fe}(\mathrm{dcpp})_{2}\right]^{2+}$ at a delay of $\sim 50 \mathrm{ps}$ following ${ }^{1} \mathrm{~A}_{1}$ $\rightarrow{ }^{1}$ MLCT excitation at $532 \mathrm{~nm}$. d) Transient $k^{2}$-weighted EXAFS spectra. $e$ ) Reconstructed excited state XANES spectra.f) Reconstructed excited state $k^{2}$-weighted EXAFS spectra.

\section{CONCLUDING COMMENTS}

We have employed time-resolved x-ray absorption and emission spectroscopies in an effort to characterize the electronic and geometric structure of $\left[\mathrm{Fe}(\mathrm{dcpp})_{2}\right]^{2+}$, an $\mathrm{Fe}(\mathrm{II})$ polypyridyl complex whose photophysical properties were sufficiently anomalous that it called into question the nature of its lowest-energy excited state. Whereas more traditional forms of steady-state and time-resolved spectroscopies were unable to definitively answer this question, the quintet spin multiplicity of this excited state has been unambiguously determined via $\mathrm{K} \alpha$ and $\mathrm{K} \beta \mathrm{XES}$, thereby establishing the lowest-energy excited state as a ${ }^{5} \mathrm{~T}_{2}$. Additional insights into the geometric changes that accompany conversion between the high-spin excited and low-spin ground states of this compound were obtained from an analysis of EXAFS data. While the average Fe-N bond elongation of $\sim 0.18 \AA$ is consistent with structural changes associated with LS $\rightarrow$ HS conversions 
in a number of other $\mathrm{Fe}(\mathrm{II})$ polypyridyl complexes, ${ }^{6,9,44,61}$ the distortion in $\left[\mathrm{Fe}(\mathrm{dcpp})_{2}\right]^{2+}$ appears to be highly anisotropic, leading to a structure that is best described in terms of pseudo Jahn-Teller distortion. This somewhat unexpected result is tentatively attributed to the nature of the dcpp ligand which allows for a degree of structural flexibility due to the manner in which it chelates to a metal as compared to complexes such as $\left[\mathrm{Fe}(\mathrm{terpy})_{2}\right]^{2+},{ }^{2}$, where the geometric constraints are expected to be more severe. . Further systematic analyses of EXAFS-derived structures of the ground and excited states of a range of Fe(II) polypyridyl complexes will be required in order to understand this as yet unresolved aspect of the present study.

Returning to the question that catalyzed this work, namely the nearly 4-fold increase in the rate constant for ground-state recovery for $\left[\mathrm{Fe}(\mathrm{dcpp})_{2}\right]^{2+}$ as compared to $\left[\mathrm{Fe}(\mathrm{bpy})_{3}\right]^{2+}$, our determination of quintet spin multiplicity for the lowest-energy excited state of $\left[\mathrm{Fe}(\mathrm{dcpp})_{2}\right]^{2+}$ means that we cannot attribute the observed difference in kinetics to a significant change in the electronic coupling between the two states (i.e., a $\Delta \mathrm{S}=1$ versus $\Delta \mathrm{S}=2$ spin change). The excitedstate relaxation kinetics of $\left[\mathrm{Fe}(\mathrm{bpy})_{3}\right]^{2+}$ in solution have long been considered to be $\mathrm{at}^{65}$ or near ${ }^{66}$ the barrierless limit, i.e., $\Delta \mathrm{G}_{0} \approx \lambda$. This was indeed one of the assumptions that led to the suggestion that perhaps the lowest energy excited state of $\left[\mathrm{Fe}(\mathrm{dcpp})_{2}\right]^{2+}$ was a ${ }^{3} \mathrm{~T}_{1}$ as opposed to ${ }^{5} \mathrm{~T}_{2}{ }^{28}$ However, it has recently been determined that ground-state recovery for $\left[\mathrm{Fe}(\mathrm{bpy})_{3}\right]^{2+}$ in fluid solution has a small but nevertheless measurable barrier of $\sim 300 \mathrm{~cm}^{-1},{ }^{67}$ whereas corresponding studies on $\left[\mathrm{Fe}(\mathrm{dcpp})_{2}\right]^{2+}$ under identical conditions reveal an essentially barrierless process with measured rate constants at $295 \mathrm{~K}$ and $215 \mathrm{~K}$ that are within experimental error of each other. ${ }^{68}$ Interestingly, the pre-exponential term in an Arrhenius treatment of the data on $\left[\mathrm{Fe}(\mathrm{bpy})_{3}\right]^{2+}$ yields a value of ca. $250 \mathrm{ps}^{-1}$, i.e., very close to the observed ground-state recovery time for $\left[\mathrm{Fe}(\mathrm{dcpp})_{2}\right]^{2+}$. Since the pre-exponential Arrhenius term is the time constant expected in the limit of zero barrier, 
we can conclude that the experimentally observed 4-fold difference in ground-state recovery time between $\left[\mathrm{Fe}(\mathrm{bpy})_{3}\right]^{2+}$ and $\left[\mathrm{Fe}(\mathrm{dcpp})_{2}\right]^{2+}$ is simply a reflection of a $\sim 300 \mathrm{~cm}^{-1}$ difference in their respective activation energies as manifested at room temperature. Given that the Arrhenius activation energy equates to $\left(\left(\Delta \mathrm{G}_{0}+\lambda\right)^{2} / 4 \lambda\right)$, it's difficult to push this analysis any further absent an independent measure of either $\Delta \mathrm{G}_{0}$ or $\lambda$. That stated, it seems plausible that the reorganization energy associated with ground-state recovery for $\left[\mathrm{Fe}(\mathrm{dcpp})_{2}\right]^{2+}$ could be larger than that of $\left[\mathrm{Fe}(\mathrm{bpy})_{3}\right]^{2+}$ given the more complex structural changes that appear to be occurring in $\left[\mathrm{Fe}(\mathrm{dcpp})_{2}\right]^{2+}$ based on the data and analysis we have presented herein. Whether that would require a larger or smaller driving force in order to compensate will depend on whether these systems lie in the normal or inverted region, an interesting question that is beyond the scope of the present study.

\section{ASSOCIATED CONTENT}

Supporting Information. UV-vis absorption spectrum, details on EXAFS analysis, estimation of activation barrier height, energies, structural parameters and natural orbitals for various electronic states of $\left[\mathrm{Fe}(\mathrm{dccp})_{2}\right]^{2+}$, Cartesian coordinates (xyz format) for optimized singlet, quintet and triplet structures of $\left[\mathrm{Fe}(\mathrm{dcpp})_{2}\right]^{2+}$ complex.

\section{AUTHOR INFORMATION}

\section{Corresponding Authors}

*abritz@slac.stanford.edu

*wojciech.gawelda@amu.edu.pl

*christian.bressler@xfel.eu 
*jkm@chemistry.msu.edu

\section{Author Contributions}

All authors have given approval to the final version of the manuscript.

\section{Notes}

The authors declare no competing financial interest.

\section{ACKNOWLEDGMENT}

This work is financed by the European XFEL, by the Deutsche Forschungsgemeinschaft (DFG) via SFB 925, project A4 (TA), and by the Hamburg Centre for Ultrafast Imaging (CUI). AB acknowledges support from the International Max Planck Research School for Ultrafast Imaging and Structural Dynamics (IMPRS-UFAST), and we acknowledge the European Cluster of Advanced Laser Light Sources (EUCALL) within work packages PUCCA (CB), which has received funding from the European Union's Horizon 2020 research and innovation programme under grant agreement No 654220. WG further acknowledges the partial financial support from the National Science Centre $(\mathrm{NCN})$ in Poland under SONATA BIS 6 grant No. 2016/22/E/ST4/00543. Work by A.M.M., G.D., S.H.S., L.Y., H.C. and R.W.S. was supported by the U.S. Department of Energy (DOE), Office of Science, Basic Energy Sciences (BES), Chemical Sciences, Geosciences, and Biosciences Division. This research used resources of the Advanced Photon Source, a U.S. Department of Energy (DOE) Office of Science User Facility operated for the DOE Office of Science by Argonne National Laboratory under contract no. DE-AC0206CH11357. ÉB, ZN, DSSz and GV were supported by the 'Lendület' (Momentum) Program of the Hungarian Academy of Sciences (LP2013-59), the Government of Hungary and the European 
Regional Development Fund under Grant VEKOP-2.3.2-16-2017-00015, and the National Research, Development and Innovation Fund (NKFIH FK 124460). ZN acknowledges support from the Bolyai Fellowship of the Hungarian Academy of Sciences. EJ, CL and SM acknowledge support from the U.S. Army Research Office under Contract W911NF-15-1-0124. The research leading to the presented results has received funding from the People Programme (Marie Curie Actions) of the European Union's Seventh Framework Programme (FP7/2007-2013) under REA grant agreement no. 609405 (MP, COFUNDPostdocDTU) and the Independent Research Fund, Denmark (MP). Fig.1 has been created with MarvinSketch and Inkscape. We are grateful to the staff of 7-ID from the APS for help during the experiment and we thank X. Zhang for support with the peristaltic pump, Diego Casa for the loan of an analyzer crystal and A. Guda for fruitful discussions. Finally, JKM gratefully acknowledges support from the Chemical Sciences, Geosciences, and Biosciences Division, Office of Basic Energy Sciences, Office of Science, U.S. Department of Energy though grant no. DE-FG02-01ER15282. 


\section{References.}

(1) Grätzel, M. Solar Energy Conversion by Dye-Sensitized Photovoltaic Cells. Inorg. Chem. 2005, 44 (20), 6841-6851.

(2) Goldsmith, J. I.; Hudson, W. R.; Lowry, M. S.; Anderson, T. H.; Bernhard, S. Discovery and High-Throughput Screening of Heteroleptic Iridium Complexes for Photoinduced Hydrogen Production. J. Am. Chem. Soc. 2005, 127 (20), 7502-7510.

(3) Ardo, S.; Meyer, G. J. Photodriven Heterogeneous Charge Transfer with Transition-Metal Compounds Anchored to $\mathrm{TiO}_{2}$ Semiconductor Surfaces. Chem. Soc. Rev. 2009, 38 (1), $115-164$.

(4) Luo, S.-P.; Mejía, E.; Friedrich, A.; Pazidis, A.; Junge, H.; Surkus, E.; Jackstell, R.; Denurra, S.; Gladiali, S.; Lochbrunner, S.; et al. Photocatalytic Water Reduction with Copper-Based Photosensitizers: A Noble-Metal-Free System. Angew. Chemie - Int. Ed. 2013, 52, 419-423.

(5) Malzner, F.; Housecroft, C.; Constable, E. The Versatile SALSAC Approach to Heteroleptic Copper(I) Dye Assembly in Dye-Sensitized Solar Cells. Inorganics 2018, 6 (57), 1-17 and references therein.

(6) Gawelda, W.; Pham, V.-T.; Benfatto, M.; Zaushitsyn, Y.; Kaiser, M.; Grolimund, D.; Johnson, S.; Abela, R.; Hauser, A.; Bressler, C.; et al. Structural Determination of a ShortLived Excited Iron(II) Complex by Picosecond X-Ray Absorption Spectroscopy. Phys. Rev. Lett. 2007, 98 (5), 057401.

(7) Haldrup, K.; Vankó, G.; Gawelda, W.; Galler, A.; Doumy, G.; March, a M.; Kanter, E. P.; Bordage, A.; Dohn, A.; van Driel, T. B.; et al. Guest-Host Interactions Investigated by Time-Resolved X-ray Spectroscopies and Scattering at MHz Rates: Solvation Dynamics and Photoinduced Spin Transition in Aqueous Fe(bipy) $3^{(2+)}$. J. Phys. Chem. A 2012, 116 (40), 9878-9887.

Zhang, W.; Alonso-Mori, R.; Bergmann, U.; Bressler, C.; Chollet, M.; Galler, A.; Gawelda, W.; Hadt, R. G.; Hartsock, R. W.; Kroll, T.; et al. Tracking Excited-State 
Charge and Spin Dynamics in Iron Coordination Complexes. Nature 2014, 509, 345-348.

(9) Vankó, G.; Bordage, A.; Pápai, M.; Haldrup, K.; Glatzel, P.; March, A. M.; Doumy, G.;

Britz, A.; Galler, A.; Assefa, T. A.; et al. Detailed Characterization of a Nanosecond-

Lived Excited State : X-Ray and Theoretical Investigation of the Quintet State in

Photoexcited [Fe(terpy)2 $]^{2+}$. J. Phys. Chem. C 2015, 119 (11), 5888-5902.

(10) Canton, S. E.; Zhang, X.; Lawson Daku, M. L.; Smeigh, A. L.; Zhang, J.; Liu, Y.;

Wallentin, C.; Attenkofer, K.; Jennings, G.; Kurtz, C. A.; et al. Probing the Anisotropic

Distortion of Photoexcited Spin Crossover Complexes with Picosecond X-ray Absorption

Spectroscopy. J. Phys. Chem. C 2014, 118 (8), 4536.

(11) Zhang, X.; Lawson Daku, M. L.; Zhang, J.; Suarez-Alcantara, K.; Jennings, G.; Kurtz, C. A.; Canton, S. E. Dynamic Jahn-Teller Effect in the Metastable High-Spin State of Solvated $\left[\mathrm{Fe}(\text { terpy })_{2}\right]^{2+}$. J. Phys. Chem. C 2015, 119 (6), 3312-3321.

(12) March, A. M.; Assefa, T. A.; Boemer, C.; Bressler, C.; Britz, A.; Doumy, G.; Galler, A.; Harder, M.; Khakhulin, D. V; Németh, Z.; et al. Probing Transient Valence Orbital Changes with Picosecond Valence-to-Core X-Ray Emission Spectroscopy. J. Phys. Chem. C 2017, 121, 2620-2626.

(13) Auböck, G.; Chergui, M. Sub-50-Fs Photoinduced Spin Crossover in $\left[\mathrm{Fe}(\mathrm{bpy})_{3}\right]^{2+}$. Nat. Chem. 2015, 7, 629-633.

(14) Ferrere, S.; Gregg, B. A. Photosensitization of $\mathrm{TiO}_{2}$ by [FeII(2,2`-bipyridine-4,4'dicarboxylic acid $\left.)_{2}(\mathrm{CN})_{2}\right]$ : Band Selective Electron Injection from Ultra-Short-Lived Excited States. J. Am. Chem. Soc. 1998, 120 (4), 843-844.

(15) McCusker, J. K.; Walda, K. N.; Dum, R. C.; Simon, J. D.; Magde, D.; Hendrickson, D. N. Subpicosecond ${ }^{1} \mathrm{MLCT}{ }^{5} \mathrm{~T}_{2}$ Intersystem Crossing of Low-Spin Polypyridyl Ferrous Complexes. J. Am. Chem. Soc. 1993, 115 (1), 298-307.

(16) Monat, J. E.; McCusker, J. K. Femtosecond Excited-State Dynamics of an Iron(II) Polypyridyl Solar Cell Sensitizer Model. J. Am. Chem. Soc. 2000, 122 (17), 4092-4097. 
(17) McCusker, J. K. Electronic Structure in the Transition Metal Block and Its Implications for Light Harvesting. Science (80-. ). 2019, 363 (6426), 484-488.

(18) De Graaf, C.; Sousa, C. Study of the Light-Induced Spin Crossover Process of the [Fe II(bpy) $]_{3}^{2+}$ Complex. Chem. - A Eur. J. 2010, 16 (15), 4550-4556.

(19) Ashley, D. C.; Jakubikova, E. Ironing out the Photochemical and Spin-Crossover Behavior of $\mathrm{Fe}(\mathrm{II})$ Coordination Compounds with Computational Chemistry. Coord. Chem. Rev. 2017, 337, 97-111.

(20) Liu, Y.; Harlang, T.; Canton, S. E.; Chábera, P.; Suárez-Alcántara, K.; Fleckhaus, A.; Vithanage, D. A.; Göransson, E.; Corani, A.; Lomoth, R.; et al. Towards Longer-Lived Metal-to-Ligand Charge Transfer States of Iron(II) Complexes: An N-Heterocyclic Carbene Approach. Chem. Commun. 2013, 49 (57), 6412-6414.

(21) Liu, Y.; Kjaer, K. S.; Fredin, L. A.; Chabera, P.; Harlang, T.; Canton, S. E.; Lidin, S.; Zhang, J.; Lomoth, R.; Bergquist, K.-E.; et al. A Heteroleptic Ferrous Complex with Mesoionic bis(1,2,3-triazol-5-ylidene) Ligands: Taming the MLCT Excited State of Iron(II). Chem. - A Eur. J. 2015, 21 (9), 3628-3639.

(22) Harlang, T. C. B.; Liu, Y.; Gordivska, O.; Fredin, L. A.; Ponseca, C. S.; Huang, P.; Chábera, P.; Kjaer, K. S.; Mateos, H.; Uhlig, J.; et al. Iron Sensitizer Converts Light to Electrons with $92 \%$ Yield. Nat. Chem. 2015, 7 (11), 883-889.

(23) Chábera, P.; Kjaer, K. S.; Prakash, O.; Honarfar, A.; Liu, Y.; Fredin, L. A.; Harlang, T. C. B.; Lidin, S.; Uhlig, J.; Sundström, V.; et al. Fe ${ }^{\mathrm{II} H e x a}$ N-Heterocyclic Carbene Complex with a 528 ps Metal-To-Ligand Charge-Transfer Excited-State Lifetime. J. Phys. Chem. Lett. 2018, 9 (3), 459-463.

(24) Fredin, L. A.; Papai, M.; Rozsályi, E.; Vanko, G.; Warnmark, K.; Sundström, V.; Persson, P. Exceptional Excited-State Lifetime of an Iron(II)-M-Heterocyclic Carbene Complex Explained. J. Phys. Chem. Lett. 2014, 5 (12), 2066-2071.

(25) Zhang, W.; Kjær, K. S.; Alonso-Mori, R.; Bergmanna, U.; Chollet, M.; Fredin, L. A.; Hadt, R. G.; Hartsock, R. W.; Harlang, T.; Kroll, T.; et al. Manipulating Charge Transfer 
Excited State Relaxation and Spin Crossover in Iron Coordination Complexes with Ligand Substitution. Chem. Sci. 2017, 8, 515-523.

(26) Shepard, S. G.; Fatur, S. M.; Rappe, A. K.; Damrauer, N. H. Highly-Strained Iron(II) Polypyridines: Exploiting the Quintet Manifold to Extend the Lifetime of MLCT Excited States. J. Am. Chem. Soc. 2016, 138 (9), 2949-2952.

(27) Fatur, S. M.; Shepard, S. G.; Higgins, R. F.; Shores, M. P.; Damrauer, N. H. A Synthetically Tunable System to Control MLCT Excited-State Lifetimes and Spin States in Iron(II) Polypyridines. J. Am. Chem. Soc. 2017, 139 (12), 4493-4505.

(28) Jamula, L. L.; Brown, A. M.; Guo, D.; McCusker, J. K. Synthesis and Characterization of a High-Symmetry Ferrous Polypyridyl Complex: Approaching the ${ }^{5} \mathrm{~T}_{2} /{ }^{3} \mathrm{~T}_{1}$ Crossing Point for Fe(II). Inorg. Chem. 2014, 53 (1), 15-17.

(29) Smeigh, A. L.; Creelman, M.; Mathies, R. A.; McCusker, J. K. Femtosecond TimeResolved Optical and Raman Spectroscopy of Photo-Induced Spin-Crossover: Temporal Resolution of Low Spin-to-High Spin Optical Switching. J. Am. Chem. Soc. 2008, 130 (43), 14105-14107.

(30) March, A. M.; Stickrath, A.; Doumy, G.; Kanter, E. P.; Krässig, B.; Southworth, S. H.; Attenkofer, K.; Kurtz, C. A.; Chen, L. X.; Young, L. Development of High-RepetitionRate Laser Pump/x-Ray Probe Methodologies for Synchrotron Facilities. Rev. Sci. Instrum. 2011, 82 (7), 73110.

(31) Walko, D. A.; Adams, B. W.; Doumy, G.; Dufresne, E. M.; Li, Y.; March, A. M.; Sandy, A. R.; Wang, J.; Wen, H.; Zhu, Y. Developments in Time-Resolved x-Ray Research at APS Beamline 7ID. AIP Conf. Proc. 2016, 1741, 1-5.

(32) Johann, H. H. Die Erzeugung Lichtstarker Röntgenspektren Mit Hilfe von Konkavkristallen. Zeitschrift für Phys. 1931, 69 (3-4), 185-206.

(33) Szlachetko, J.; Nachtegaal, M.; de Boni, E.; Willimann, M.; Safonova, O.; Sa, J.; Smolentsev, G.; Szlachetko, M.; van Bokhoven, J. A.; Dousse, J.-C.; et al. A von Hamos X-Ray Spectrometer Based on a Segmented-Type Diffraction Crystal for Single-Shot X- 
Ray Emission Spectroscopy and Time-Resolved Resonant Inelastic x-Ray Scattering Studies. Rev. Sci. Instrum. 2012, 83, 103105.

(34) Ejdrup, T.; Lemke, H. T.; Haldrup, K.; Nielsen, T. N.; Arms, D. A.; Walko, D. A.; Miceli, A.; Landahl, E. C.; Dufresne, E. M.; Nielsen, M. M. Picosecond Time-Resolved Laser Pump/X-Ray Probe Experiments Using a Gated Single-Photon-Counting Area Detector. J. Synchrotron Radiat. 2009, 16 (3), 387-390.

(35) Becke, A. D. Density-Functional Thermochemistry. III. The Role of Exact Exchange. J. Chem. Phys. 1993, 98 (7), 5648-5652.

(36) Becke, A. D. A New Mixing of Hartree-Fock and Local Density-Functional Theories. J. Chem. Phys. 1993, 98 (2), 1372-1377.

(37) Lee, C.; Yang, W.; Parr, R. G. Development of the Colle-Salvetti Correlation-Energy Formula into a Functional of the Electron Density. Phys. Rev. B 1988, 37 (2), 785-789.

(38) Stephens, P. J.; Devlin, F. J.; Chabalowski, C. F.; Frisch, M. J. Ab Initio Calculation of Vibrational Absorption and Circular Dichroism Spectra Using Density Functional Force Fields. J. Phys. Chem. 1994, 98 (45), 11623-11627.

(39) Grimme, S. Semiempirical GGA-Type Density Functional Constructed with a LongRange Dispersion Correction. J. Comput. Chem. 2006, 27 (15), 1787-1799.

(40) Dolg, M.; Wedig, U.; Stoll, H.; Preuss, H. Energy-Adjusted Ab Initio Pseudopotentials for the First Row Transition Elements. J. Chem. Phys. 1987, 86 (2), 866-872.

(41) Francl, M. M.; Pietro, W. J.; Hehre, W. J.; Binkley, J. S.; Gordon, M. S.; DeFrees, D. J.; Pople, J. A. Self-Consistent Molecular Orbital Methods. XXIII. A Polarization-Type Basis Set for Second-Row Elements. J. Chem. Phys. 1982, 77 (7), 3654-3665.

(42) Hariharan, P. C.; Pople, J. A. The Influence of Polarization Functions on Molecular Orbital Hydrogenation Energies. Theor. Chim. Acta 1973, 28 (3), 213-222.

(43) Hehre, W. J.; Ditchfield, K.; Pople, J. A. Self-Consistent Molecular Orbital Methods. XII. 
Further Extensions of Gaussian-Type Basis Sets for Use in Molecular Orbital Studies of Organic Molecules. J. Chem. Phys. 1972, 56 (5), 2257-2261.

(44) Scalmani, G.; Frisch, M. J. Continuous Surface Charge Polarizable Continuum Models of Solvation. I. General Formalism. J. Chem. Phys. 2010, 132 (11), 1-15.

(45) Bowman, D. N.; Bondarev, A.; Mukherjee, S.; Jakubikova, E. Tuning the Electronic Structure of Fe(II) Polypyridines via Donor Atom and Ligand Scaffold Modifications: A Computational Study. Inorg. Chem. 2015, 54 (17), 8786-8793.

(46) Nance, J.; Bowman, D. N.; Mukherjee, S.; Kelley, C. T.; Jakubikova, E. Insights into the Spin-State Transitions in $\left[\mathrm{Fe}(\mathrm{tpy})_{2}\right]^{2+}$ : Importance of the Terpyridine Rocking Motion. Inorg. Chem. 2015, 54 (23), 11259-11268.

(47) Frisch, M. J.; Trucks, G. W.; Schlegel, H. B.; Scuseria, G. E.; Robb, M. A.; Cheeseman, J. R.; Scalmani, G.; Barone, V.; Mennucci, B.; Petersson, G. A.; et al. Gaussian 09 Rev. D.01; Gaussian, Inc.: Wallingford, CT, USA. 2009.

(48) Becke, A. D. Density-Functional Exchange-Energy Approximation with Correct Asymptotic Behavior. Phys. Rev. A 1988, 38 (6), 3098-3100.

(49) Perdew, J. P. Density-Functional Approximation for the Correlation Energy of the Inhomogeneous Electron Gas. Phys. Rev. B 1986, 33 (2), 8822-8824.

(50) Te Velde, G.; Bickelhaupt, F. M.; Baerends, E. J.; Fonseca Guerra, C.; van Gisbergen, S. J. A.; Snijders, J. G.; Ziegler, T. Chemistry with ADF. J. Comput. Chem. 2001, 22 (9), 931-967.

(51) Fonseca Guerra, C.; Snijders, J. G.; te Velde, G.; Baerends, E. J. Towards and Order-N DFT Method. Theor. Chem. Acc. 1998, 99, 391-403.

(52) ADF2013, SCM, Theoretical Chemistry, Vrije Universiteit, Amsterdam, The Netherlands http://www.scm.com (accessed May 3, 2018).

(53) Huse, N.; Kim, T. K.; Jamula, L.; McCusker, J. K.; de Groot, F. M. F.; Schoenlein, R. W. 
Photo-Induced Spin-State Conversion in Solvated Transition Metal Complexes Probed via Time-Resolved Soft X-Ray Spectroscopy. J. Am. Chem. Soc. 2010, 132 (19), 6809-6816.

(54) Cho, H.; Strader, M. L.; Hong, K.; Jamula, L.; Gullikson, E. M.; Kim, T. K.; de Groot, F. M. F.; McCusker, J. K.; Schoenlein, R. W.; Huse, N. Ligand-Field Symmetry Effects in Fe(II) Polypyridyl Compounds Probed by Transient X-Ray Absorption Spectroscopy. Faraday Discuss. 2012, 157, 463.

(55) Van Kuiken, B. E.; Khalil, M. Simulating Picosecond Iron K-Edge X-Ray Absorption Spectra by Ab Initio Methods To Study Photoinduced Changes in the Electronic Structure of Fe(II) Spin Crossover Complexes. J. Phys. Chem. A 2011, 115 (39), 10749-10761.

(56) Vankó, G.; Glatzel, P.; Pham, V.-T.; Abela, R.; Grolimund, D.; Borca, C. N.; Johnson, S. L.; Milne, C. J.; Bressler, C. Picosecond Time-Resolved X-Ray Emission Spectroscopy: Ultrafast Spin-State Determination in an Iron Complex. Angew. Chemie - Int. Ed. 2010, 49, 5910-5912.

(57) Vankó, G.; Bordage, A.; Glatzel, P.; Gallo, E.; Rovezzi, M.; Gawelda, W.; Galler, A.; Bressler, C.; Doumy, G.; March, A. M.; et al. Spin-State Studies with XES and RIXS: From Static to Ultrafast. J. Electron Spectros. Relat. Phenomena 2013, 188, 166-171.

(58) Vankó, G.; Neisius, T.; Molnar, G.; Renz, F.; Karpati, S.; Shukla, A.; de Groot, F. M. F. Probing the 3d Spin Momentum with X-Ray Emission Spectroscopy: The Case of Molecular-Spin Transitions. J. Phys. Chem. B 2006, 110 (24), 11647-11653.

(59) Glatzel, P.; Bergmann, U. High Resolution 1s Core Hole X-Ray Spectroscopy in 3d Transition Metal Complexes - Electronic and Structural Information. Coord. Chem. Rev. 2005, 249 (1-2), 65-95.

(60) Ravel, B.; Newville, M. ATHENA, ARTEMIS, HEPHAESTUS: Data Analysis for X-Ray Absorption Spectroscopy Using IFEFFIT. J. Synchrotron Radiat. 2005, 12 (Pt 4), 537541.

(61) Sayers, D. E.; Stern, E. A.; Lytle, F. New Technique for Investigating Noncrystalline Structures: Fourier Analysis of the Extended X-Ray- Absorption Fine Structure*. Phys. 
Chem. Lett. 1971, 27 (18), 1204.

(62) Ankudinov, A. L.; Rehr, J. J.; Conradson, S. D. Real-Space Multiple-Scattering Calculation and Interpretation of x-Ray-Absorption near-Edge Structure. Phys. Rev. B 1998, 58 (12), 7565-7576.

(63) Biasin, E.; Driel, T. B. Van; Kjær, K. S.; Dohn, A. O.; Christensen, M.; Harlang, T.; Chabera, P.; Liu, Y.; Uhlig, J.; Pápai, M.; et al. Femtosecond X-Ray Scattering Study of Ultrafast Photoinduced Structural Dynamics in Solvated [Co(Terpy)2]2+. Phys. Rev. Lett. 2016, 117, 013002.

(64) Zhang, J.; Zhang, X.; Suarez-alcantara, K.; Jennings, G.; Kurtz, C. A.; Daku, L.; Canton, S. E. Resolving the Ultrafast Changes of Chemically Inequivalent Metal - Ligand Bonds in Photoexcited Molecular Complexes with Transient X - Ray Absorption Spectroscopy. ACS Omega 2019, 4, 6375-6381.

(65) Khalil, M.; Marcus, M. a; Smeigh, A. L.; McCusker, J. K.; Chong, H. H. W.; Schoenlein, R. W. Picosecond X-Ray Absorption Spectroscopy of a Photoinduced Iron(II) Spin Crossover Reaction in Solution. J. Phys. Chem. A 2006, 110, 38-44.

(66) Sutin, N. Nuclear, Electronic, and Frequency Factors in Electron Transfer Reactions. Acc. Chem. Res. 1982, 15 (14), 275-282.

(67) Hauser, A.; Vef, A.; Adler, P. Intersystem Crossing Dynamics in Fe(II) Coordination Compounds. J. Chem. Phys. 1991, 95 (12), 8710-8717.

(68) Carey, M. C.; Adelman, S. L.; McCusker, J. K. Insights in the Excited State Dynamics of Fe(II) Polypyridyl Complexes from Variable-Temperature Ultrafast Spectroscopy. Chem. Sci. 2018, 10 (134).

(69) Carey, M. C. Achieving a Long-Lived Charge-Separated Fe(II) Chromophore: Insights into the Role of Reorganization Energy on the Ultrafast Photophysical Processes of D6 Polypyridyl Complexes, Ph.D. Dissertation, Michigan State University, East Lansing, MI, 2018. 


\section{FOR TABLE OF CONTENTS ONLY}

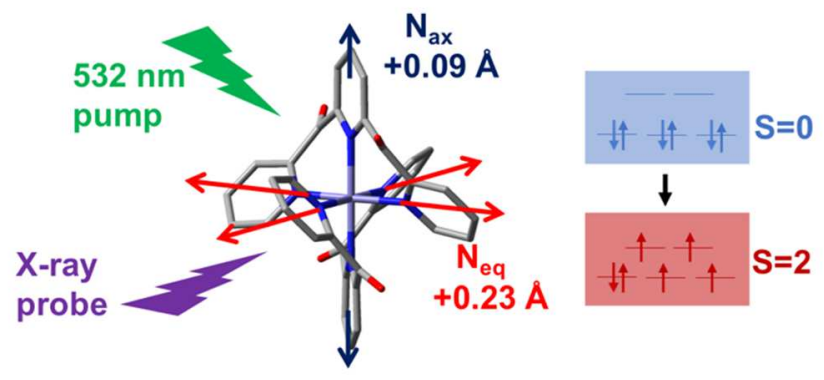

\section{SYNOPSIS}

Time-resolved x-ray emission and absorption spectroscopies have been used to probe the excitedstate electronic and geometric structure of an Fe(II) polypyridyl complex. Analysis of the data revealed that the lowest energy excited state is high-spin $(S=2)$ in character. This determination had not been possible using other experimental techniques (e.g., time-resolved optical spectroscopy), demonstrating the potential for ultrafast x-ray methods to address scientific questions that are difficult to resolve by other means. 